attempted a book at this level, I have had an ideal reader in mind - myself aged 16, largely ignorant but reasonably intelligent, and willing to make a serious effort if the prize in understanding seemed worth it. I would have loved this book at 16 , and so should anyone - aged 16 to 60 - who really wants to understand development.

John Maynard Smith is at the School of Biological Sciences, University of Sussex, Falmer, Brighton BN1 9QG, UK.

\section{Surfing a chaotic sea}

\section{Physics of Chaos in Hamiltonian \\ Systems}

by G. M. Zaslavsky

World Scientific: 1998.268 pp. $£ 30, \$ 44$

\section{J.D.Meiss}

Remarkably, the basic models of motion in physics - ranging from Newton's law of gravitation to modern string theory - can all be formulated as Hamiltonian dynamical systems. Here there is a striking pairing between position coordinates (configuration variables) and their rates of change (momentum variables). Each such pair of variables constitutes a 'degree of freedom' of the system. Hamiltonian dynamics normally conserves energy, but this need not be the case; for example, a frictionless pendulum with an oscillating support is a nonconservative Hamiltonian system. Time dependence is considered a 'half' degree of freedom. The goal of Physics of Chaos is to explore the structures and motion of systems with one and a half degrees of freedom.

Hamiltonian dynamics can show extraordinary complexity when the number of degrees of freedom exceeds one. This complexity gives rise to 'fractal' images that are just as visually engaging as the famed Mandelbrot set, and its study is vital for understanding everything from chemical reaction rates to the stability of the Solar System.

Computer studies show that the motion consists of islands of stability in a sea of chaos. These islands can even mimic quasicrystalline patterns. Some of our understanding of such systems can be traced back to Poincaré, but many questions remain. The major one addressed here is: can statistical techniques be applied to such chaotic motion? While these methods apply to 'uniformly' chaotic systems, the ubiquitous islands of stability lead to long correlations that contravene the use of standard statistical (for example, diffusive) techniques. The theory of transport in such systems relies on the geometry of the stable manifolds and of the 'cantori' (structures that act as nearly impermeable barriers) that permeate the chaotic sea; this has been carefully treated by Stephen Wiggins in Chaotic Transport in Dynamical Systems (Springer, 1991).

\title{
Rhythms of the human heart
}

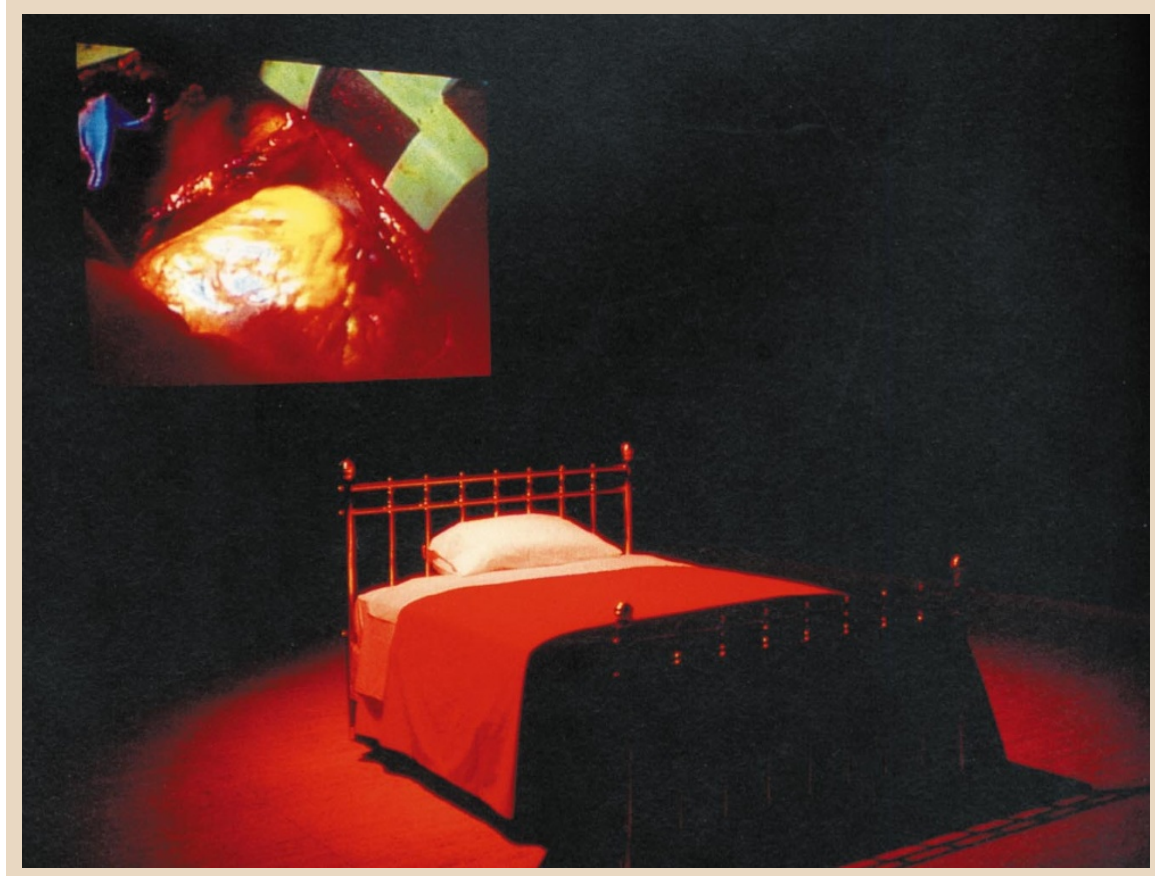

A human heartbeat forms the background to Bill Viola's video installation, "Science of the Heart". His work - showing at Frankfurt's Museum für Moderne Kunst until April, in San

George Zaslavsky develops 'fractional kinetics' in an attempt to give a smoothed, but nondiffusive, description. This phenomenological description captures some aspects of the stickiness of islands, but I believe its mathematical justification remains elusive. Perhaps that is an excellent reason to read this book.

J. D. Meiss is in the Department of Applied

Mathematics, University of Colorado, Boulder, Colorado 80309, USA.

\section{A bloody business}

\section{Blood: An Epic History of Medicine and Commerce}

by Douglas Starr

Knopf: 1998. 440 pp. \$27.50, £20

\section{Fred S. Rosen}

While the value of a barrel of crude oil has fallen to $\$ 12$, an equivalent amount of blood is now worth around $\$ 60,000$. How this came about is lucidly recounted by Douglas Starr in this history of blood transfusion. The book has received broad critical acclaim in the lay press and is indeed accessible to a wide-ranging audience.

From its murky beginnings in the eighteenth century, blood transfusion became a practical reality in this century through the efforts of many unsung heroes. In 1908, Alexis Carrel, working at the Rockefeller Institute in New York, successfully transfused a profoundly anaemic newborn baby
Francisco from June and in Chicago from October till January 2000 — is also displayed in the book Bill Viola by the Whitney Museum of American Art (Flammarion, \$60, £39.95).

by connecting her physician father's radial artery to the infant's popliteal vein with a cannula. Soon after, Richard Lewisohn at the Mount Sinai Hospital in New York showed that sodium citrate could be used to prevent blood coagulation without harming the blood or its recipient. By this time, Karl Landsteiner had discovered the ABO bloodgroup system and two of his students, Philip Levine and Alexander Weiner, subsequently discovered the rhesus (Rh) blood groups. The First World War dramatized the need for blood and blood products to combat shock and other complications of the wounded. The elements were in place for the birth of the blood-banking industry.

The Western democracies and the USSR made great strides during the Second World War in delivering dried plasma and albumin to the battlefield, as fleetingly portrayed in the opening scenes of the recent movie Saving Private Ryan. The Germans were bogged down in attempts to preserve the racial purity of the blood supply, a folly matched only by the Americans' rules to segregate the blood of black Americans. It is ironic that a distinguished black American physician directed the first large-scale blood collection in the United States at the beginning of the Second World War - Charles Drew directed the Plasma for Britain campaign.

The outstanding work of Edwin J. Cohn at Harvard Medical School in fractionating plasma into its useful components is described with all the details of showmanship that Cohn conjured up. 
But then the darker side of this history reveals itself in the emergence of tainted blood drawn from donors in search of cash. A dismaying chapter in this history involves blood collection for money in Central America and other underdeveloped countries from people in desperate financial need. The problems of hepatitis transmission were soon overshadowed by the contamination of the blood supply by the human immunodeficiency virus (HIV).

Then there is the frightening tale of the deadly triumph of the free market. When the Community Blood Bank of Kansas City, Missouri, became the favoured source of blood for physicians because a local commercial blood-donor centre was collecting contaminated blood, the United States Federal Trade Commission accused the physicians of illegal conspiracy to restrain free trade! A fine of $\$ 5,000$ a day was imposed until blood was purchased from the contaminated commercial source.

The last part of the book looks at the now twice-told tale of HIV contamination of anti-haemophilic factor, and the bitter resentments and ugly legal squabbles that ensued. The former French prime minister Laurent Fabius was acquitted only a few weeks ago - to the dismay of many, in what Starr calls cathartic national breast-beating.

Many significant contributors to blood banking do not appear in this book. There is no mention of Allen Latham, who at Cohn's instigation invented the blood-cell separator, the so-called Latham bowl. The monumental struggle of Harvard surgeon Carl Walter with the US Food and Drug Administration to get blood out of breakable glass bottles and into malleable plastic bags is given only brief mention. And the late Wallace Coulter, who standardized blood counting worldwide with his Coulter counter, invented in the basement of a Chicago boarding-house using the Cellophane wrapper from a pack of Lucky Strike cigarettes during the Second World War, gets no space.

There are many more books to be written about all this. And the blood supply is once again safe - until the next unknown bloodborne virus creeps up on us.

Fred S. Rosen is in the Department of Pediatrics, Harvard Medical School, Longwood Avenue, Boston, Massachusetts 02115, USA.

\section{Storm-chaser reaps the whirlwind}

\section{Tornado Alley: Monster Storms of the Great Plains \\ by Howard B. Bluestein \\ Oxford University Press: 1998.170 pp. \$35, $\mathfrak{E} 17.99$}

\section{Roger A. Pielke Sr}

Howie Bluestein is the man who made 'storm-chasing' scientifically acceptable. A pioneer in the field observation and measurement of tornadoes and tornadic thunderstorms, he blends history and science with his personal experiences in a book that will be enjoyed by anyone who is interested in these intense atmospheric whirlwinds. It should also help clear up any misunderstandings that resulted from seeing the recent film Twister!

Though the text is very detailed in places, non-specialists can safely skim the technical sections without losing the point. The use of degrees Fahrenheit and feet may be annoying to some readers, but the numbers can easily be converted to metric units.

The book analyses other people's experiences of tornadoes as well as drawing on

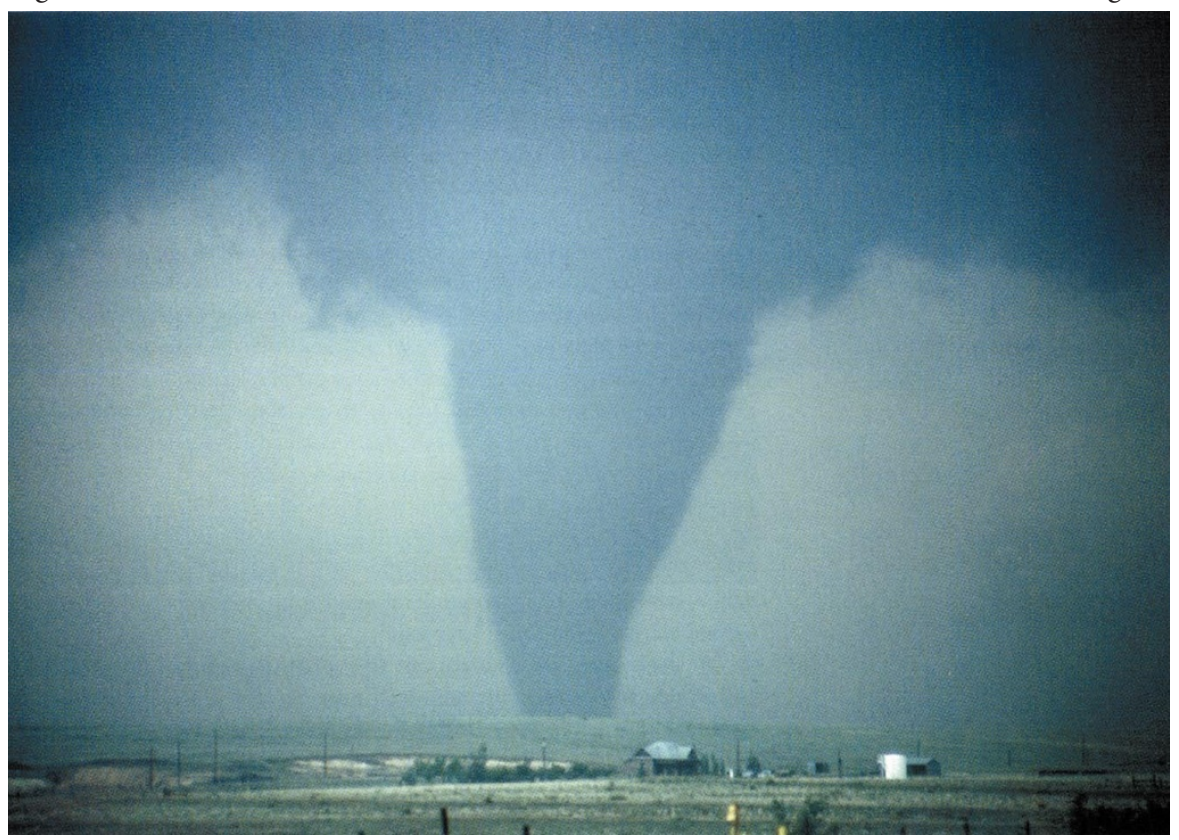

Threatening clouds: a tornado in its mature phase looms over the town of Canadian, Texas, in 1986.
Bluestein's personal perspective. It includes a useful discussion of the Fujita scale of intensity, which was introduced by Ted Fujita of the University of Chicago and has now become accepted by the public.

Bluestein looks at the use of computers to simulate tornadic thunderstorms: the correspondence between computer modelling and the actual behaviour of thunderstorms is remarkable. Unfortunately, he does not mention some important recent work by Louie Grasso of the US National Oceanic and Atmospheric Administration and Cathy Finley of the University of Northern Colorado. These two have, separately, simulated the development of actual tornadoes - Finley has even simulated the development and dissipation of their suction vortices. Bluestein also overlooks the modelling work of researchers such as Bob Walko while at the University of Oklahoma, and Conrad Ziegler at the National Severe Storms Laboratory.

Because of the major role he has played in field campaigns studying 'Tornado Alley' in the Great Plains of the United States, Bluestein is often seen in television shows on this now-popular subject. In fact, tornadoes have a long history on our screens. Bluestein's TOTO - the Totally Totable Observatory, a canister packed with meteorological instruments and used in some of his earlier field campaigns - was named after Dorothy's dog in The Wizard of Oz. (Twister was based on attempts to insert these instruments into the path of tornadoes.) The discussion of TOTO in this book is a pleasure to read.

Readers interested in an overview of measurement systems will appreciate Bluestein's explanations of facilities spanning the size range from helicopters and remotely piloted vehicles to the latest model TOTO II. Portable rawinsondes and Doppler radars, Doppler lidars, millimetrewavelength radars and airborne Doppler radars - each of these offers a unique way to monitor tornadoes.

What next? Bluestein's speculation on the future of tornado research, as one of the scientific leaders in this field, makes important reading. For his part, he is likely to continue to play an active role in their investigation.

For further reading, the book lists relevant websites and other sources of tornado information. The outstanding set of videos prepared by the Tornado Project in St Johnsbury, Vermont, should be added to the list (http://www.tornadoproject. com).

In conclusion, this book by an internationally recognized expert in his subject is an enjoyable read. The scientific understanding of tornadoes is increasing all the time, and Bluestein masterfully weaves his experiences together with his insights into this constantly evolving field of research.

Roger A. Pielke Sr is in the Department of Atmospheric Science, Colorado State University, Fort Collins, Colorado 80523, USA. 